Article

\title{
Characterizing the Health of Older Rural Australians Attending Rural Events: Implications for Future Health Promotion Opportunities
}

\author{
Tracy L. Schumacher ${ }^{1,2}{ }^{\mathbb{D}}$, Laura Alston ${ }^{3,4,5}{ }^{\mathbb{D}}$, Luke Wakely ${ }^{1}$, Rachel Latter ${ }^{6}$, Kelly Squires ${ }^{1}$ (D), \\ Susan Heaney ${ }^{1,2}$ iD and Leanne J. Brown $1,2, * \mathbb{D}$
}

Citation: Schumacher, T.L.; Alston, L.; Wakely, L.; Latter, R.; Squires, K.;

Heaney, S.; Brown, L.J.

Characterizing the Health of Older Rural Australians Attending Rural Events: Implications for Future Health Promotion Opportunities. Int. J. Environ. Res. Public Health 2022, 19, 3011. https://doi.org/10.3390/ ijerph19053011

Academic Editor: Paul B Tchounwou

Received: 17 January 2022

Accepted: 2 March 2022

Published: 4 March 2022

Publisher's Note: MDPI stays neutral with regard to jurisdictional claims in published maps and institutional affiliations.

Copyright: (C) 2022 by the authors. Licensee MDPI, Basel, Switzerland. This article is an open access article distributed under the terms and conditions of the Creative Commons Attribution (CC BY) license (https:// creativecommons.org/licenses/by/ $4.0 /)$.
1 Department of Rural Health, University of Newcastle, Tamworth, NSW 2340, Australia; tracy.schumacher@newcastle.edu.au (T.L.S.); luke.wakely@newcastle.edu.au (L.W.); kelly.squires@newcastle.edu.au (K.S.); susan.heaney@newcastle.edu.au (S.H.)

2 Hunter Medical Research Institute, New Lambton Heights, NSW 2305, Australia

3 Research Department, Colac Area Health, Colac, VIC 3707, Australia; laura.alston@deakin.edu.au

4 The Global Obesity Centre, Institute for Health Transformation, School of Medicine, Faculty of Health, Deakin University, Geelong, VIC 3220, Australia

5 Deakin Rural Health, Deakin University, Warrnambool, VIC 3280, Australia

6 St. George Hospital, South Eastern Sydney Local Health District, Kogarah, NSW 2217, Australia; rachel.latter@health.nsw.gov.au

* Correspondence: leanne.brown@newcastle.edu.au; Tel.: +61-267-553-540

\begin{abstract}
This paper describes the health of older Australians ( $>65$ years) attending rural events to inform health promotion interventions for rural populations. This cross-sectional study collected survey data and objective health measures between 2017 and 2020 at two events held in rural New South Wales, Australia. Participants included in the analysis were adults $>65$ years of age. Data included demographic and health information, anthropometric measures (height, weight, waist circumference), and dietary and physical activity data. A total of 256 people $>65$ years participated. Our sample, which was mostly male (59.0\%), contained people aged between 66 and 75 years $(72.3 \%)$. Participants lived in either a large rural $(34.0 \%)$ or small rural town $(22.3 \%)$, with low levels of education (60.9\% did not complete high school). Dietary quality was rated as below average. All but $17.2 \%$ of the participants reported having a health condition. The risk of a health condition was associated with increasing age, lower education, and higher waist circumference, but not remoteness. Rural events may provide an opportunity to access, engage with, and understand the health of older rural Australians, especially males. They may offer ideal contexts for health and nutrition promotion opportunities in rural areas where access to health professionals is limited.
\end{abstract}

Keywords: rural health; nutrition; health promotion; health status; older adults

\section{Introduction}

Older individuals make up a considerable proportion of Australia's population, with more than one in seven people being aged 65 years and over [1]. It is estimated that by 2022, four million Australians will be aged 65 and over, which is expected to be followed by a rapid increase in the proportion of this age group over the next decade [2]. For this group, the World Health Organization (WHO) (Geneva, Switzerland) definition of healthy ageing as "the process of developing and maintaining the functional ability that enables wellbeing in older age" applies [3]. Chronic diseases become increasingly prevalent and can significantly impact economic, social, and physical aspects of quality of life [4]. A focus on health promotion for the generation and maintenance of optimal health and nutrition in an ageing population is key to an improved quality of life and a reduced impact on health services in the future. 
One in two people aged 65 years and over are diagnosed with one or more chronic diseases, such as cardiovascular disease, cancer, diabetes, chronic kidney disease, and mental health conditions $[4,5]$. Over one-third of disease burden could be prevented by reducing or eliminating exposure to modifiable risk factors, including poor nutrition, physical inactivity, smoking, and harmful use of alcohol [6-8]. Where people live may influence exposure to modifiable risk factors and, therefore, can further increase the risk of developing chronic disease [9]. In addition, health and risk factor data for those living in rural areas in Australia are limited, resulting in a lack of evidence-informed action and policy $[10,11]$.

Older Australians are less likely to live in major cities compared to the general population, with one-third of older Australians living in regional or remote areas in 2016 [1]. Rural and remote areas of Australia can be classified by the Modified Monash Model which takes into account population size and remoteness of the geographical area as well as access to services [12]. These areas tend to be heterogenous in nature; however, on average, they have poorer health outcomes compared to metropolitan communities [13,14]. The reasons for this are complex and multifactorial [13-16]; however, the health inequities have been widely acknowledged to be unjust and preventable $[10,17]$. Issues such as geographical isolation, limited access to health services, lower education and health literacy levels, differences in modifiable risk factors, lower socioeconomic status, and a lack of evidence to inform health policy, compared to metropolitan communities, contribute to these health outcomes for older people in these areas $[9,10,13-16,18]$. Rurality has been shown to be a risk factor for chronic diseases, over and beyond the influence of factors such as socio-economic status [19]. Health inequalities in the burden of chronic diseases among rural Australians are well documented in the Australian literature; however, health promotion initiatives to date have often failed to address the unique needs of rural communities $[17,20]$.

Despite the known health inequalities experienced by rural Australians, a recent review found that there is only limited evidence of nutrition interventions in rural areas, with an urgent need for further research in rural communities [21]. Rural people are underrepresented in existing health data sets [22] and due to their geographical location are more challenging to access and engage in health promotion opportunities $[23,24]$. Previous health-related activities have been conducted at a rural agricultural events in Australia, with one specifically focused on the health of men who self-presented to a health promotion activity [25]. Most participants in this study were rural-based, with a median age of 56 years and had 'at risk' health characteristics [25].

Large rural events offer an opportunity to obtain health data and to promote health improvements in this population [25]. Many of these events intend to bring geographically isolated communities together to showcase agricultural practices, produce products, and/or to promote tourism which provides social and economic benefits [26-28]. There are many rural-based events across Australia each year and they may appeal to different groups with variations in the age, gender, and rurality of those attending. These events provide an opportunity to engage with these populations, with access to healthy and 'at risk' rural people to provide health and nutrition promotion [25].

Health promotion initiatives may alleviate the increased social and economic burden in Australia and globally due to the growing ageing population and concomitant chronic disease rates [2]. Targeted health promotion for older rural people may support successful ageing with an increased interest in health promotion programs for this target group [24] Internationally, researchers have found that health promotion is challenging in rural communities, with practitioner, client, and site factors restricting what can be done [23,24]. Opportunities exist to provide health and nutrition promotion at events attended by large numbers of rural people.

\section{The CHAaRGE:20 Study}

The Changing Health Actions at Rural and Regional Events in 20 min (CHAaRGE:20) is a health promotion initiative that aims to address health and nutrition issues for populations 
attending rural-based events. The CHAaRGE: 20 stall delivers 20 min health checks at ruralbased events and provides participants with individualized feedback (brief nutrition and health promotion) on their health and nutrition measures. During these health checks, anthropometric measurements are taken, and health and demographic data are collected to increase the understanding of the health issues prevalent in the population. Over the various events, a range of health measures have been trialed as practical and useful approaches for opportunistic health promotion. This larger data set has informed the development of brief nutrition and health promotion materials, along with changes to the health check assessment components.

In order to develop appropriate health and nutrition interventions for rural people, a greater understanding of their health status and health promotional tools is needed. Older rural Australians can be supported to improve their health as they age, with consideration of the individual and collective factors that impact on their wellbeing. A greater understanding of ways to connect and engage with them are key to supporting improvements through health- and nutrition-focused promotional activities [29]. This is a novel study as it utilizes existing events where rural people gather in large numbers to collect data about their nutrition and health status in order to inform future health promotion that is targeted to suit their needs and stage of life. Understanding the health and nutrition issues of older rural Australians will support initiatives to improve their health with age.

The aim of this paper is to characterize the health and nutrition of older Australians ( $>65$ years) that attended a free health promotion stall in two rural sites to inform future health promotion opportunities.

\section{Materials and Methods}

This was a cross-sectional study with data collected between 2017 and 2020 at two regional event sites in New South Wales (NSW), Australia.

\subsection{Participants and Setting}

Adults aged $\geq 18$ years were eligible for the health check activity. Participants needed to be able to read and follow instructions in English and physically able to stand for height and weight measures. However, only people providing their age as over 65 years were included in this analysis, with the full data set for all age groups reported elsewhere in an analysis of diet quality [30]. Attendees under the influence of drugs or alcohol were considered ineligible. Recruitment was undertaken at two event sites: (i) AgQuip, a threeday agricultural field day based in Gunnedah, NSW in August (2017-2019); and (ii) the Tamworth Country Music Festival (TCMF), held in January (2018-2020). Data for AgQuip were typically collected for the entire three-day period between 9:00 a.m. and 4:00 p.m. every day at the University of Newcastle Department of Rural Health (UONDRH) site at the AgQuip field day. The TCMF site was located within an air-conditioned shopping complex, although complexes changed between 2018 and 2019/2020. Both complexes had access to locals and visitors attending the events, and data were typically collected between 9:00 a.m. and 4:00 p.m. Although the TCMF officially runs between mid- and late-January annually, the study only recruited at the site for three or four days (Monday-Thursday) during the ten-day festival.

Participants were recruited opportunistically at the events. Study information flyers were distributed by student volunteers, UONDRH social media (Facebook and Twitter), local media, word of mouth, and direct participant enquiry at the UONDRH health exhibition. The stall was staffed by UONDRH academic health professional staff and students. Qualified health professionals and students with training in the study recruitment and data collection processes were able to perform aspects of the research process.

Ethical approval was obtained from the University of Newcastle Human Research Ethics Committee (H-2017-0197) and was conducted in accordance with the National Statement on Ethical Conduct in Human Research. Informed consent was obtained prior to the collection of data and measurements. 


\subsection{The Health Check Activity}

Data collection took approximately $20 \mathrm{~min}$ per participant. The survey and health measurements were undertaken as part of a health check where participant privacy was provided using large screens within an open space area. Each participant was provided with a participant information statement and was able to complete their consent to participate on an iPad. Participants were allocated a unique study identification number. At the end of the health check, participants were provided with their health assessment results and a comparative recommended or average score.

\subsection{Demographic and Health Survey}

A demographic and health survey was completed by participants on iPads provided and participants were assisted by student dietitians or researchers if needed. Key demographic and health information collected included residential location, measures of socioeconomic status, education and employment, smoking status, and dental health and medical history. Australian Physical Activity Guidelines were used to compare cohort physical activity data for AgQuip 2019 onwards [31]. All questions consisted of multiplechoice options. The survey was managed using the online Survey Monkey program in 2017 and Research Electronic Data Capture (REDCap) software in 2018 [32]. Some categories with small numbers of respondents were collapsed.

\subsection{Geographic Location}

Rurality was categorized into the Modified Monash Model [12], which provides a classification of Australian cities and towns from Modified Monash (MM) 1 to 7: MM1—metropolitan, MM2 — regional centers, MM3 - large rural towns, MM4 —-medium rural towns, MM5—small rural towns, MM6 - remote communities, and MM7—very remote communities. By using postcode, the description of where someone lived (in town/out of town/don't wish to answer), the size of the nearest town $(<5000 / 500-15,000 / 15,000-50,000 / 50,000+$ people $)$, and the size of their land if the "out of town" descriptor was chosen (large house block/hobby farm/small farm/medium farm/large farm/don't wish to answer). A postcode with a single MM categorization was given that categorization, regardless of any further information provided. Some postcodes had more than one MM categorization e.g., the postcode 2340 may be categorized as MM3 (large rural town) or MM4 (medium rural town). When further information was provided, i.e., with answers of "in town", "large house block", "hobby farm", "small farm", and "medium farm", these were attributed to the MM value for that postcode and town size. Those choosing "out of town" and "large farm" were attributed an MM code consistent with being $20 \mathrm{~km}$ from a town within that postcode. Where limited information was available, or other factors made the MM attribution unclear, the lowest MM value for that postcode was given.

\subsection{Dietary Intake}

Dietary intake was assessed using the online Healthy Eating Quiz $[33,34]$ at the health checks undertaken in 2017. In 2018, this was changed to the optional completion of the Australian Eating Survey (AES) [35], as quiz completion was slower than expected. Within the survey, participants had the option to provide their email address and to complete the AES online at a later time. An automated email was sent using REDCap with a link to the AES being delivered to consenting participants upon completion of the demographic and health survey. A reminder was sent approximately 1-2 weeks post-event for those who had not completed the survey or if their survey was incomplete. The AES is a detailed dietary questionnaire designed to collect information regarding an individual's usual intake and dietary patterns. Both the Healthy Eating Quiz and AES generate the same diet quality score for the Australian Recommended Food Score (ARFS) [36]. The ARFS ranges from 0 to 73, and questions align with foods in the core food groups of The Australian Guide to Healthy Eating [37]. Scores are categorized as "needs work" (<33), "getting there" (33-38), "excellent" (39-46), or "outstanding' (47+)". 


\subsection{Anthropometry}

Anthropometry measures were recorded by trained research assistants according to International Society for the Advancement of Kinanthropometry (ISAK) protocols. A portable BSM370 stadiometer, corrected to $0.1 \mathrm{~cm}$ and $0.01 \mathrm{~kg}$ (Biospace Co., Ltd., Seoul, Korea), was used to measure participant height and weight. Waist circumference was measured on the skin using a metallic, non-extensible Lufkin WP606PM tape measure at the narrowest point between the lower costal border and the iliac crest. Waist circumference was categorized as increased risk at $80 \mathrm{~cm}$ for women and $94 \mathrm{~cm}$ for men, and greatly increased risk at $88 \mathrm{~cm}$ and $102 \mathrm{~cm}$ for women and men, respectively [38]. Prior to all anthropometric measures, participants were asked to remove their shoes and any heavy items on their person such as belt, watch and/or phones. Measures were recorded a minimum of two times for each participant and the average of these was recorded. In cases where variation in measures was $>2 \%$, an additional measure was taken. An average was calculated from the two closest measures. Body mass index (BMI) was calculated as $\mathrm{kg} / \mathrm{m}^{2}$ and categorized into 'underweight, healthy weight, overweight and obese' [39]. From 2018, participants were also asked to estimate their own weight. This was divided by their actual weight and multiplied by 100 to calculate the percentage of actual weight that was estimated.

\subsection{Statistical Analysis}

Data were managed using Survey Monkey in 2017 and REDCap from 2018 onwards and analyzed using Stata/IC Version 15.1 (StataCorp. 2017. Stata Statistical Software: StataCorp LLC, College Station, TX, USA). Descriptive statistics were used to describe participant demographics and health characteristics, with normally distributed variables presented as mean \pm standard deviation (SD). Percentages of respondents were given where possible. A Kruskal-Wallis equality of populations was used to test equality in health characteristics between those who responded to the diet questionnaire, and those who did not. A linear regression was used to test whether rurality contributed to a person's total number of self-reported health conditions. Health conditions (high blood pressure or high cholesterol, renal disease, diabetes, cancer, mental health, musculoskeletal conditions, or respiratory conditions) were self-reported, based on if they had been told they had this by a health professional. An adjusted model contained contributing factors that were decided a priori, based on literature and whether they had been consistently collected over the recruiting period. Therefore, rurality classified by MMM, age, gender, education, and waist circumference were included in the model. Using pmsampsize (Riley 2020) and based on an r-squared value of 0.1 , five parameters, an intercept of 2, and a sample size of 239 people were needed.

\section{Results}

A total of 638 participants completed all the required components of the study. Of these, $n=256$ were aged over 65 years of age (therefore $n=382$ was excluded). No people were turned away for not meeting the inclusion criteria. Participant demographic information for these people is summarized in Table 1.

Table 1. CHAaRGE:20 study participants (aged over 65 years) demographic information by rural event.

\begin{tabular}{|c|c|c|c|c|c|c|}
\hline & \multicolumn{2}{|c|}{ AgQuip } & \multicolumn{2}{|c|}{ TCMF } & \multicolumn{2}{|c|}{ Total } \\
\hline & $n=105$ & $(100 \%)$ & $n=151$ & $(100 \%)$ & $n=256$ & $(100 \%)$ \\
\hline \multicolumn{7}{|l|}{ Age } \\
\hline $66-70$ years & 38 & $(36.2 \%)$ & 61 & $(40.4 \%)$ & 99 & $(38.7 \%)$ \\
\hline $71-75$ years & 40 & $(38.1 \%)$ & 46 & $(30.5 \%)$ & 86 & $(33.6 \%)$ \\
\hline $76-80$ years & 20 & $(19.1 \%)$ & 27 & $(17.9 \%)$ & 47 & $(18.4 \%)$ \\
\hline $81+$ years & 7 & $(6.7 \%)$ & 17 & $8.6 \%)$ & 24 & $(9.4 \%)$ \\
\hline
\end{tabular}


Table 1. Cont.

\begin{tabular}{|c|c|c|c|c|c|c|}
\hline & \multicolumn{2}{|c|}{ AgQuip } & \multicolumn{2}{|c|}{ TCMF } & \multicolumn{2}{|c|}{ Total } \\
\hline & $n=105$ & $(100 \%)$ & $n=151$ & $(100 \%)$ & $n=256$ & $(100 \%)$ \\
\hline \multicolumn{7}{|l|}{ Gender } \\
\hline Male & 74 & $(70.5 \%)$ & 77 & $(51.0 \%)$ & 151 & $(59.0 \%)$ \\
\hline Female & 31 & $(29.5 \%)$ & 74 & $(49.0 \%)$ & 105 & $(41.0 \%)$ \\
\hline \multicolumn{7}{|l|}{$\begin{array}{l}\text { MM rural categorization } \\
\text { (live in or near) }\end{array}$} \\
\hline $1-$ metropolitan area & 12 & $(11.4 \%)$ & 45 & $(29.8 \%)$ & 57 & $(22.3 \%)$ \\
\hline 2 -regional centre & 2 & $(1.9 \%)$ & 10 & $(6.6 \%)$ & 12 & $(4.7 \%)$ \\
\hline 3-large rural town & 24 & $22.9 \%)$ & 63 & $(41.7 \%)$ & 86 & $(34.0 \%)$ \\
\hline 4-medium rural town & 24 & $(22.9 \%)$ & 7 & $(4.6 \%)$ & 31 & $(12.1 \%)$ \\
\hline 5-small rural town & 37 & $(35.2 \%)$ & 20 & $(13.3 \%)$ & 57 & $(22.3 \%)$ \\
\hline 6-7-remote-very remote community & 3 & $(2.9 \%)$ & 1 & $(0.7 \%)$ & 4 & $(1.6 \%)$ \\
\hline Missing & 3 & $(2.9 \%)$ & 5 & $(3.3 \%)$ & 8 & $(3.1 \%)$ \\
\hline \multicolumn{7}{|l|}{ Education } \\
\hline Less than year 12 & 60 & $(57.1 \%)$ & 96 & $(63.6 \%)$ & 156 & $(60.9 \%)$ \\
\hline Year 12 & 8 & $(7.6 \%)$ & 18 & $(11.9 \%)$ & 26 & $(10.2 \%)$ \\
\hline Trade or vocation & 18 & $(17.1 \%)$ & 25 & $(16.6 \%)$ & 43 & $(16.8 \%)$ \\
\hline University or above & 17 & $(16.2 \%)$ & 10 & $(6.6 \%)$ & 27 & $(10.6 \%)$ \\
\hline $\begin{array}{l}\text { None above/missing/don't wish to } \\
\text { answer }\end{array}$ & 2 & $(1.9 \%)$ & 2 & $(1.3 \%)$ & 4 & $(1.6 \%)$ \\
\hline \multicolumn{7}{|l|}{ Household income } \\
\hline Pension & 33 & $(31.4 \%)$ & 43 & $(28.5 \%)$ & 76 & $(29.7 \%)$ \\
\hline AUD 0-499/week & 18 & $(17.1 \%)$ & 30 & $19.9 \%)$ & 48 & $(18.8 \%)$ \\
\hline AUD 500-999/week & 14 & $(13.3 \%)$ & 19 & $(12.6 \%)$ & 33 & $(12.9 \%)$ \\
\hline AUD 1000-1999/week & 11 & $(10.5 \%)$ & 25 & $(16.6 \%)$ & 36 & $(14.1 \%)$ \\
\hline AUD 2000+/week & 6 & $(5.7 \%)$ & 3 & $(2.0 \%)$ & 9 & $(3.5 \%)$ \\
\hline Don't know/wish to answer & 23 & $(21.9 \%)$ & 31 & $(20.5 \%)$ & 54 & $(21.1 \%)$ \\
\hline \multicolumn{7}{|l|}{ People dependent on this income } \\
\hline 1 & 39 & $(37.1 \%)$ & 67 & $(44.4 \%)$ & 106 & $(41.4 \%)$ \\
\hline $2-3$ & 59 & $(56.2 \%)$ & 77 & $51.0 \%)$ & 136 & $(53.1 \%)$ \\
\hline $4-6$ & 3 & $(2.9 \%)$ & 2 & $(1.3 \%)$ & 5 & $(2.0 \%)$ \\
\hline Don't wish to answer/missing data & 4 & $(3.8 \%)$ & 5 & $(3.3 \%)$ & 9 & $(3.5 \%)$ \\
\hline \multicolumn{7}{|l|}{ Living arrangements * } \\
\hline Live alone & 29 & $(27.6 \%)$ & 50 & $(33.1 \%)$ & 79 & $(30.9 \%)$ \\
\hline With partner/spouse & 71 & $(67.6 \%)$ & 94 & $(62.3 \%)$ & 165 & $(64.5 \%)$ \\
\hline Own children or other's children & 5 & $(4.8 \%)$ & 10 & $(6.6 \%)$ & 15 & $(5.9 \%)$ \\
\hline Other adults & 6 & $(5.7 \%)$ & 7 & $(4.6 \%)$ & 13 & $(5.1 \%)$ \\
\hline
\end{tabular}

Abbreviations: AUD-Australian Dollars; MM-Modified Monash; TCMF-Tamworth Country Music Festival * Note that people were able to tick more than one box with this question.

Risk factors for chronic disease, such as weight status, smoking, physical activity, and dietary estimates, can be seen in Table 2. It shows few differences between people attending the two different rural events. According to World Health Organization BMI categorization, the majority of people were overweight $(n=117,45.7 \%)$, with $33.2 \%$ classed as obese $(n=85)$, and the remainder as normal weight $(n=54,21.1 \%)$. BMI was $29.4 \mathrm{~kg} / \mathrm{m}^{2}$ (4.0) for men and $26.6 \mathrm{~kg} / \mathrm{m}^{2}$ (4.4) for women. Men weighed a mean of $88.8 \mathrm{~kg}(12.0)$, while women weighed $68.7 \mathrm{~kg}(12.4)$. Of the 68 people $(26.6 \%)$ categorized as "increased risk" according to their waist circumference, the distribution was similar for men and women ( $27.2 \%$ and $25.7 \%$, respectively). However, of the 140 (54.7\%) with a waist circumference of "greatly increased risk", males represented more of the sample $(59.6 \%$ males and $47.6 \%$ females). Waist circumference was $105.1 \mathrm{~cm}$ (12.6) for men and $87.8 \mathrm{~cm}$ (11.7) for women. Across the total sample, $14.8 \%$ stated they had recently lost weight.

It must be noted that most people were accurate in estimating their weight. With $100 \%$ representing complete accuracy, the median accuracy was $98.9 \%$, with an interquartile range of $97.5 \%$ to $100.6 \%$. Approximately $6.2 \%$ of the sample population estimated a weight more than $5 \%$ lower than their measured weight, and only $2.7 \%$ provided an estimation 
more than $5 \%$ above their measured weight. There was no statistical difference in accuracy between gender $(p=0.32)$ or event $(p=0.94)$.

Of the 161 participants who were asked about their physical activity, the preferred method of physical activity was walking, with $74.7 \%$ of the TCMF participants and $84.1 \%$ of AgQuip participants performing this activity for one hour or more each week. Despite $85.7 \%$ of respondents answering that they are active on most days, only $52.8 \%$ also said they felt they got enough physical activity.

On average, the proportion of energy from energy dense, non-nutritious foods was $30 \%$. The Healthy Eating Quiz was completed by 23 participants, prior to changing the dietary measure to the optional AES, which was completed by 54 participants. The mean ARFS score was 36.2 (SD 8.5) ( $n=77)$, which rates as 'getting there', with no difference between events. Of those who completed the optional AES, the average energy contributed by core foods was $69.9 \%$ of total intake.

Table 2. Description of risk factors of CHAaRGE:20 study participants (aged over 65) attending the rural events.

\begin{tabular}{|c|c|c|c|c|c|c|}
\hline \multirow[b]{2}{*}{ Smoking status } & \multicolumn{2}{|c|}{ AgQuip } & \multicolumn{2}{|c|}{ TCMF } & \multicolumn{2}{|c|}{ Total } \\
\hline & $n=105$ & $(\mathbf{1 0 0 \% )}$ & $n=151$ & $(100 \%)$ & $n=256$ & $(100 \%)$ \\
\hline Currently smoke & 1 & $(1.0 \%)$ & 3 & $(2.0 \%)$ & 4 & $(1.6 \%)$ \\
\hline Do not currently smoke & 104 & $99.1 \%)$ & 147 & $(97.4 \%)$ & 251 & $(98.1 \%)$ \\
\hline Missing data & 0 & $(0 \%)$ & 1 & $(0.7 \%)$ & 1 & $(0.4 \%)$ \\
\hline Weight status $(n=256)$ & $n=105$ & $(100 \%)$ & $n=151$ & $(100 \%)$ & $n=256$ & $(100 \%)$ \\
\hline \multicolumn{7}{|l|}{ Weight over the last 6 months } \\
\hline Been losing or have lost weight & 15 & $(14.3 \%)$ & 23 & $(15.2 \%)$ & 38 & $(14.8 \%)$ \\
\hline Maintained weight & 55 & $(52.4 \%)$ & 91 & $(60.3 \%)$ & 146 & $(57.0 \%)$ \\
\hline Gained weight & 12 & $(11.4 \%)$ & 32 & $(21.2 \%)$ & 44 & $(17.2 \%)$ \\
\hline \multirow[t]{2}{*}{ Not sure or missing data } & 23 & $(21.9 \%)$ & 5 & $(1.3 \%)$ & 28 & $(10.9 \%)$ \\
\hline & mean & (sd) & mean & $(\mathrm{sd})$ & mean & (sd) \\
\hline Est. weight (kg, $n=224, \mathrm{n} / \mathrm{a}$ AgQuip 2017) & 84.5 & $(19.0)$ & 77.6 & $(17.1)$ & 80.0 & $(18.1)$ \\
\hline Measured weight $(\mathrm{kg}, n=255)$ & 83.8 & $(16.0)$ & 78.2 & $(17.6)$ & 80.5 & $(17.1)$ \\
\hline Measured BMI $(n=255)$ & 28.9 & $(3.9)$ & 27.8 & $(4.7)$ & 28.2 & $(4.4)$ \\
\hline Measured waist circumference $(\mathrm{cm})$ & 100.5 & $(14.2)$ & 97.0 & $(15.7)$ & 98.4 & $(15.2)$ \\
\hline Physical Activity * (those answering 'yes') & $n=82$ & $(100 \%)$ & $n=79$ & $(100 \%)$ & $n=161$ & $(\mathbf{1 0 0 \%})$ \\
\hline $\begin{array}{l}\text { Do you feel you participate in enough } \\
\text { physical activity? }\end{array}$ & 45 & $(54.9 \%)$ & 40 & $(50.6 \%)$ & 85 & $(52.8 \%)$ \\
\hline Active on most days of every week & 70 & $(85.4 \%)$ & 68 & $(86.1 \%)$ & 138 & $(85.7 \%)$ \\
\hline $\begin{array}{l}\text { Moderate }(150-300 \mathrm{~min}) \text { or vigorous } \\
\text { activity }(75-150 \mathrm{~min}) / \text { week }\end{array}$ & 60 & $(73.2 \%)$ & 67 & $(84.8 \%)$ & 127 & $(78.9 \%)$ \\
\hline Muscle strengthening at least 2 days/week & 32 & $(39.0 \%)$ & 27 & $(34.2 \%)$ & 59 & $(36.7 \%)$ \\
\hline \multicolumn{7}{|l|}{ Activities for 1 or more hours in the last week } \\
\hline $\begin{array}{l}\text { Physical activity, e.g., swimming, jogging, } \\
\text { tennis, gym }\end{array}$ & 14 & $(17.1 \%)$ & 20 & $(25.3 \%)$ & 34 & $(21.1 \%)$ \\
\hline Cycling & 7 & $(8.5 \%)$ & 7 & $(8.9 \%))$ & 14 & $(8.7 \%)$ \\
\hline Walking & 69 & $(84.1 \%)$ & 59 & $(74.7 \%)$ & 128 & $(79.5 \%)$ \\
\hline Housework & 41 & $(50.0 \%)$ & 43 & $(54.4 \%)$ & 84 & $(52.2 \%)$ \\
\hline Gardening/Do It Yourself activities & 36 & $(43.9 \%)$ & 39 & $(49.4 \%)$ & 75 & $(46.6 \%)$ \\
\hline Barriers to physical activity * & $n=37$ & $(100 \%)$ & $n=39$ & $(100 \%)$ & 76 & $(100 \%)$ \\
\hline Pain, injury or illness & 10 & $(27.0 \%)$ & 11 & $(28.2 \%)$ & 21 & $(27.6 \%)$ \\
\hline Too tired & 3 & $(8.1 \%)$ & 6 & $(15.4 \%)$ & 9 & $(11.8 \%)$ \\
\hline No easy access & 4 & $(10.8 \%)$ & 4 & $(10.3 \%)$ & 8 & $(10.6 \%)$ \\
\hline No time & 12 & $(32.4 \%)$ & 11 & $(28.2 \%)$ & 23 & $(30.3 \%)$ \\
\hline Too expensive & 1 & $(2.7 \%)$ & 3 & $(7.7 \%)$ & 4 & $(5.3 \%)$ \\
\hline Weather makes physical activity difficult & 0 & $(0.0 \%)$ & 9 & $(23.1 \%)$ & 9 & $(11.8 \%)$ \\
\hline $\begin{array}{l}\text { Lack of trained people to show how } \\
\text { to participate }\end{array}$ & 1 & $(2.7 \%)$ & 1 & $(2.6 \%)$ & 2 & $(2.6 \%)$ \\
\hline Unsure of how to participate & 3 & $(8.1 \%)$ & 6 & $(15.4 \%)$ & 9 & $(11.8 \%)$ \\
\hline
\end{tabular}


Table 2. Cont.

\begin{tabular}{|c|c|c|c|c|c|c|c|}
\hline \multirow[b]{2}{*}{ Diet } & & \multicolumn{2}{|c|}{ AgQuip } & \multicolumn{2}{|c|}{ TCMF } & \multicolumn{2}{|c|}{ Total } \\
\hline & & mean & (sd) & mean & (sd) & mean & (sd) \\
\hline & ARFS $(n=77, \text { AgQuip }=41 / \mathrm{TCMF}=36)^{\wedge}$ & 35.5 & (8.5) & 36.9 & (8.6) & 36.2 & $(8.5)$ \\
\hline & $\begin{array}{l}\% \text { energy from recommended food sources } \\
(n=54, \text { AgQuip }=18 / \mathrm{TCMF}=36)\end{array}$ & 71.2 & $(11.0)$ & 69.3 & $(11.2)$ & 69.9 & $(11.1)$ \\
\hline & $\begin{array}{l}\% \text { energy from energy dense, nutrient } \\
\text { poor foods } \\
(n=54, \text { AgQuip }=18 / \mathrm{TCMF}=36)\end{array}$ & 28.8 & $(11.0)$ & 30.8 & $(11.3)$ & 30.1 & $(11.1)$ \\
\hline
\end{tabular}

The number of responses varied according to when questions were added to surveys used. Therefore, $n$ values are presented for each section. * Physical activity questions added to intervention in prior to AgQuip 2019 Only people who answered NO to whether they participated in enough physical activity were asked about barriers. ^No significant difference in Australian Recommended Food Score (ARFS) between those completing the Healthy Eating Quiz and Australian Eating Survey; Abbreviations: ARFS-Australian Recommended Food Score; BMI-body mass index; Est-estimated; TCMF-Tamworth Country Music Festival.

Oral health and reported health conditions can be found in Table 3. Although oral health data were not available for the 2017 AgQuip period, it shows that the majority of the population retains all or some of their own teeth.

Table 3. Description of self-reported health conditions and medications, as identified by self or told by a health practitioner.

\begin{tabular}{|c|c|c|c|c|c|c|}
\hline \multirow[t]{2}{*}{ Self-Reported Health Information } & \multicolumn{2}{|c|}{ AgQuip } & \multicolumn{2}{|c|}{ TCMF } & \multicolumn{2}{|c|}{ Total } \\
\hline & $n=105$ & $(100 \%)$ & $n=151$ & $(100 \%)$ & $n=256$ & $(100 \%)$ \\
\hline \multicolumn{7}{|l|}{ Oral Health } \\
\hline Care for own teeth & 79 & $(75.2 \%)$ & 146 & $(96.7 \%)$ & 225 & $(87.9 \%)$ \\
\hline \multicolumn{7}{|l|}{ Have a dry mouth } \\
\hline Always & 5 & $(4.8 \%)$ & 12 & $(8.0 \%)$ & 17 & $(6.6 \%)$ \\
\hline Sometimes & 33 & $(31.4 \%)$ & 68 & $(45.0 \%)$ & 101 & $(39.5 \%)$ \\
\hline \multicolumn{7}{|l|}{ Have sore spots in your mouth } \\
\hline Always & 1 & $(1.0 \%)$ & 2 & $(1.3 \%)$ & 3 & $(1.2 \%)$ \\
\hline Sometimes & 4 & $(3.8 \%)$ & 12 & $(8.0 \%)$ & 16 & $(6.3 \%)$ \\
\hline Infrequently & 3 & $(2.9 \%)$ & 7 & $(4.6 \%)$ & 10 & $(3.9 \%)$ \\
\hline \multicolumn{7}{|l|}{ Have own teeth } \\
\hline Own teeth & 46 & $(43.8 \%)$ & 67 & $(44.4 \%)$ & 113 & $(44 \%)$ \\
\hline Combination own teeth/dentures & 30 & $(28.6 \%)$ & 62 & $(41.1 \%)$ & 92 & $(35.9 \%)$ \\
\hline Full set of dentures & 5 & $(4.7 \%)$ & 19 & $(12.6 \%)$ & 24 & $(9.4 \%)$ \\
\hline Missing data & 24 & $(22.9 \%)$ & 3 & $(2.0 \%)$ & 27 & $(10.6 \%)$ \\
\hline \multicolumn{7}{|l|}{ Health conditions ${ }^{\wedge}$} \\
\hline High blood pressure or high cholesterol & 52 & $(49.5 \%)$ & 83 & $(55.0 \%)$ & 135 & $(52.7 \%)$ \\
\hline Chronic kidney or renal disease & 4 & $(3.8 \%)$ & 2 & $(1.3 \%)$ & 6 & $(2.3 \%)$ \\
\hline Diabetes (Type 1, 2 gestational or other) & 12 & $(11.4 \%)$ & 17 & $(11.3 \%)$ & 29 & $(11.3 \%)$ \\
\hline Overweight or obesity & 23 & $(21.9 \%)$ & 18 & $(11.9 \%)$ & 41 & $(16.0 \%)$ \\
\hline Cancer (any type) & 26 & $(24.8 \%)$ & 22 & $(14.6 \%)$ & 48 & $(18.8 \%)$ \\
\hline $\begin{array}{l}\text { Anxiety, depression, schizophrenia or any other } \\
\text { mental health condition }\end{array}$ & 14 & $(13.3 \%)$ & 16 & $(10.6 \%)$ & 30 & $(11.7 \%)$ \\
\hline $\begin{array}{l}\text { Back problems, osteoporosis, osteoarthritis and } \\
\text { rheumatoid arthritis or any other } \\
\text { musculoskeletal condition }\end{array}$ & 49 & $(46.7 \%)$ & 68 & $(45.0 \%)$ & 117 & $(45.7 \%)$ \\
\hline Asthma, COPD or any other lung condition & 19 & $(18.1 \%)$ & 24 & $(15.9 \%)$ & 43 & $(16.8 \%)$ \\
\hline None of these conditions & 17 & $(16.2 \%)$ & 27 & $(17.9 \%)$ & 44 & $(17.2 \%)$ \\
\hline
\end{tabular}


Table 3. Cont.

\begin{tabular}{|c|c|c|c|c|c|c|}
\hline \multirow[t]{2}{*}{ Self-Reported Health Information } & \multicolumn{2}{|c|}{ AgQuip } & \multicolumn{2}{|c|}{ TCMF } & \multicolumn{2}{|c|}{ Total } \\
\hline & $n=105$ & $(100 \%)$ & $n=151$ & $(100 \%)$ & $n=256$ & $(\mathbf{1 0 0 \%})$ \\
\hline \multicolumn{7}{|l|}{ Take regular medications for these health conditions } \\
\hline High blood pressure or high cholesterol & 49 & $(53.3 \%)$ & 77 & $(49.0 \%)$ & 126 & $(49.2 \%)$ \\
\hline Chronic kidney or renal disease & 3 & $(2.9 \%)$ & 0 & $(0.0 \%)$ & 3 & $(1.2 \%)$ \\
\hline Diabetes & 9 & $(8.6 \%)$ & 14 & $(9.3 \%)$ & 23 & $(9.0 \%)$ \\
\hline Overweight or obesity & 0 & $(0 \%)$ & 0 & $(0 \%)$ & 0 & $(0 \%)$ \\
\hline Cancer & 1 & $(1.0 \%)$ & 0 & $(0 \%)$ & 1 & $(0.4 \%)$ \\
\hline $\begin{array}{l}\text { Anxiety, depression, schizophrenia or any other } \\
\text { mental health condition }\end{array}$ & 4 & $(3.8 \%)$ & 8 & $(5.3 \%)$ & 12 & $(4.7 \%)$ \\
\hline $\begin{array}{l}\text { Back problems, osteoporosis, osteoarthritis and } \\
\text { rheumatoid arthritis or any other } \\
\text { musculoskeletal condition }\end{array}$ & 15 & $(14.3 \%)$ & 34 & $(22.5 \%)$ & 49 & $(19.1 \%)$ \\
\hline Asthma, COPD or any other lung condition & 7 & $(6.7 \%)$ & 17 & $(11.3 \%)$ & 24 & $(9.4 \%)$ \\
\hline \multicolumn{7}{|l|}{ Reason for the health check } \\
\hline Because it was free & 20 & $(19.1 \%)$ & 22 & $(14.6 \%)$ & 42 & $(16.4 \%)$ \\
\hline I wanted to find out more about my health & 44 & $(41.9 \%)$ & 48 & $(31.8 \%)$ & 92 & $(35.9 \%)$ \\
\hline It's been a while since I had a health check & 11 & $(10.5 \%)$ & 5 & $(3.3 \%)$ & 16 & $(6.3 \%)$ \\
\hline My partner/spouse/friend etc. said I should & 10 & $(9.5 \%)$ & 7 & $(4.6 \%)$ & 17 & $(6.6 \%)$ \\
\hline I wanted to help with research about rural health & 20 & $(19.1 \%)$ & 17 & $(11.3 \%)$ & 37 & $(14.5 \%)$ \\
\hline
\end{tabular}

Only those who answered YES are described in the table. ^ Question asked was "Have you ever been told by a doctor or health professional that you have any of these conditions?" Abbreviations: chronic obstructive pulmonary disease-COPD; TCMF-Tamworth Country Music Festival.

On average, participants 1.8 (SD 1.2) health conditions and took medication for 0.93 (SD 0.83) for those conditions. Notably, approximately half of those who chose to undertake a health check $(n=22,54.4 \%)$ were on a pension. The number of health conditions and BMI did not differ between those who had completed the dietary questionnaire and those who did not ( $p=0.085$ and $p=0.352$ respectively).

Rurality did not contribute to the number of health conditions a person reported they had, as advised by a health professional $(p=0.194)$, although age, education, and waist circumference all had significant associations (see Table 4). In this sample, the number of health conditions increased by 0.2 for each year of age (95\% confidence interval (CI): $0.050-0.345)$. Each higher level of education decreased health conditions by approximately 0.18 (95\% CI: $-0.318--0.040)$, and each centimeter of waist circumference increased health conditions by 0.016 ( $95 \% \mathrm{CI}$ : $0.006-0.025)$.

Table 4. Unadjusted and adjusted regression results for whether rurality is a significant contributor to the number of health conditions a person reported they had been told by a health professional. Model fit for the adjusted regression was $p<0.001$ and adjusted R-squared was 0.1002 .

\begin{tabular}{lcccc}
\hline & Coefficient & Std. Err. & $p$ Value & 95\% Confidence Interval \\
\hline MMM (unadjusted) & 0.095 & 0.053 & 0.072 & $-0.008-0.199$ \\
MMM (adjusted) & 0.072 & 0.075 & 0.178 & $-0.033-0.350$ \\
Age & 0.202 & 0.075 & 0.008 & $0.053-0.345$ \\
Gender & 0.173 & 0.196 & 0.378 & $-0.213-0.558$ \\
Education & -0.158 & 0.070 & 0.025 & $-0.296--0.203$ \\
Waist circumference & 0.016 & 0.006 & 0.032 & $0.006-0.031$ \\
\hline
\end{tabular}

Abbreviations: MMM-Modified Monash Model.

\section{Discussion}

This paper characterizes the health of a sample of largely rural dwelling Australians over 65 years of age, a population that has been historically under-researched resulting in minimal evidence to inform health promotion priorities for this age group [40]. Of most interest was that our population were predominantly male $(59 \%)$, which addresses important gaps in the evidence as, broadly speaking, males tend to be difficult to recruit in 
health research, especially in rural areas [41,42]. Overall, most of the population $(72.3 \%)$ were aged between 66 and 75 years of age and lived in either a large rural (MM3 34.0\%) or small rural (MM5 22.3\%) town, with lower levels of education (most of our sample reported that they had not completed high school (60.9\% of participants)). All but $17.2 \%$ of the participants reported that they had a health condition, and the risk of a health condition was associated with increasing age, lower education status, and higher waist circumference, consistent with the wider literature [4,5]. Having a health condition was not found to be associated with remoteness in this sample, in comparison to larger Australian studies that have been inclusive across a wider age range $[17,19]$. This may be due to the smaller and more male-dominated sample analyzed in this context, which is novel compared to previous research.

There is a need for ongoing health promotion in rural areas with a focus on education for improved nutrition, healthy weight, good oral health, and the management of chronic health conditions. Improving nutrition is key to the optimization of health for the elderly who live in rural areas, as it can support weight loss and assist in management of chronic conditions. Key messages for dietary change are to achieve more variety from core food groups and to reduce energy dense nutrient poor foods in order to improve overall diet quality.

Our data were largely reflective of estimates from national health surveys in Australia, with most of the participants being in the overweight and obese category $(78.9 \%)$ compared with the national estimate of $75.6 \%$ for this age group [1,43]. In contrast, only a small number $(1-3 \%)$ of this sample reported being a current smoker compared to $6-7 \%$ of over65-year-olds in national data [1]. This may be due to selection bias, with the opportunistic nature of the health checks and the likelihood that people attending wanted to know more about their health and are more likely to engage in more healthful behaviors as a result [44]. Our findings support the existing literature for this age group, i.e., that walking followed by housework and gardening are the most preferred forms of physical activity. This is consistent with another large Australian study that also investigated barriers and facilitators to physical activity in older people [45]. Similarly, our population identified pain as a main barrier to exercise $(27.6 \%$ in the current study compared to $26 \%$ previous estimates) with both time and tiredness also being reported as barriers, albeit time being a greater barrier in this current study $(30 \%)$ and only $12 \%$ in the previously published study [45]. Most participants (78.9\%) reported that they engaged in the recommended 150 to $300 \mathrm{~min}$ of exercise per week. Conversely, national data describe that $71.9 \%$ of those aged 65 years and over do not meet the recommended level of physical activity [43]. This may again be reflective of selection bias in our study, where more health interested participants are more likely to attend the health checks and participate in research [43].

Despite the high proportion of overweight and obesity in this sample, $14.8 \%$ reported that they had recently lost weight. Our study did not explore the reasons behind this, and whether the weight loss was intentional. This is an important consideration for future research, as there is evidence to suggest that rural-dwelling Australians are at an increased risk of malnutrition, especially in the over-65-year-old age group [46]. Furthermore, participants reported that a high proportion of their daily energy intake was from non-nutritious energy dense foods, which may both contribute to overweight and obesity, alongside the risk of malnutrition [47]. This is important as both overweight, obesity, and malnutrition contribute to poorer health outcomes, making this population especially vulnerable [47]. Globally, clinical guidelines have attempted to take this into account, through debate over what is considered the 'healthy weight range' for those aged over 65 years. Guidelines for clinical settings suggest that the ideal BMI range for older people is $27-30 \mathrm{~kg} \mathrm{~m}^{2}$, arguing that increased weight is protective in the event of acute illness [48]. Despite this, national data for this age group are reported alongside the WHO guidelines of a BMI of $>25 \mathrm{~m}^{2}$ as being considered overweight or obese. With most of our sample reporting that they have existing health conditions, consideration around the healthy BMI range is needed, and should be explored in future health promotion initiatives. Perhaps reflective of this 
lack of consistency, only $16 \%$ of participants had been told by their doctor that they were overweight or obese, despite a high proportion in our sample. This may also be indicative of the lack of access to general practitioners and health professionals in rural settings, reducing the opportunity for such discussions to take place $[9,49,50]$.

Importantly, there is a paucity of literature focused on interventions to improve dietary behaviors in rural areas [21]. Our sample, with an average ARFS of 36.2 (SD 8.5), had comparable diet quality scores with a larger sample of Australian adults aged 65-74+ years, where ARFS ranged between 35.8 (15.3) and 37.2 (SD 8.5) [33]. This equates to a diet quality categorized as 'getting there'. In our previously reported comparison of diet quality with CHAaRGE:20 participants of other age groups, those aged over 71 years had higher scores for diet quality compared to 18-30-year-old participants [30]. Several risk factors that relate to lower diet quality were reported here. For example, previous research has shown that living alone is one such risk factor $[30,33]$. Approximately one third of this sample lived alone, and is consistent with other populations [1]. Our study similarly showed that the oral health reported here is also consistent with national data, such as having a dry mouth and sore spots, and this may affect nutritional intake [1,51]. The relationship between diet quality and chronic diseases is well known [52]. Risk factors related to nutrition require further consideration when tailoring health promotion initiatives specifically for this age group.

This study shows that such events provide an ideal setting for health promotion initiatives which aim to improve health. Brief nutritional interventions have been shown to have a positive impact on short-term dietary behaviors, particularly if education and instructional component are tailored to individuals [53]. Targeted nutrition interventions, focused on fruit and vegetable intake, fat intake, and/or diet quality, included a consultation with personalized feedback, as opposed to generic nutrition information, which resulted in a positive improvement in dietary change (low fat dairy intakes at 1-month follow-up) at 6 and 12 months [53].

Older Australians are more likely to live in rural and remote areas and are vulnerable to health inequalities observed between differing levels of remoteness than people aged under $65[9,20]$. Recruitment of older adults at these rural events was higher than the relative proportion of those over 65 years living outside of an Australian capital city [54]. Our study shows that rural events are a useful setting for recruiting rural and remote Australians over the age of 65, especially males. In particular, events focused on agriculture may provide a valuable opportunity to engage with males, as our study achieved a higher proportion of male participation at this type of event. Our study provided an ideal opportunity for gaining new understandings and implementing health promotion initiatives. In this study, we were able to easily recruit a large sample, with a high response rate to most questions. Most of the participants also indicated that they visited the health check because they wanted to know more about their health, which again could be reflective of a lack of access to health services in rural settings [17]. This study highlights the opportunities rural events offer in collecting data that advances understandings of the health of people in nonmetropolitan areas. Rural events also offer an opportunity for brief health promotion and education initiatives, as most participants were not highly educated but were motivated to know more about their health.

Although our study presents comprehensive data on a historically understudied population, it is evident that further research is needed with this age group. Investment in health promotion initiatives that consider a focus on addressing weight in this group, balancing the risk of malnutrition, and providing advice around managing pain and exercise is needed. This study also provides evidence that there is a need for health promotion initiatives that target both the prevention and management of oral health issues. Future research also needs to consider how rurally based health professionals can better approach conversations around weight status in this age-group, as well as how this can be appropriately addressed to reduce the risk of new or worsening non-communicable disease in this age group. 
A strength of this study is it provides a data set on an under-researched population that used survey tools based on national data collection questions and objectively measured weight and height by trained health researchers. The data were also collected at two separately located events over four years, adding to the strength and generalizability of the dataset. A potential limitation to this data is that the people attending the health check may have been more health-conscious, therefore presenting different conditions and behaviors compared to the general population. This particularly extends to those with dietary data obtained from completed AES. This study also relied on self-report for most of the data collection, which is also subject to reporting bias. However, our data largely reflected findings from recent national surveys, indicating representativeness. Questions and subsequent data collection evolved over time, and this has meant limited responses in some areas. A further limitation is that changing to voluntary completion of the AES limited the number of dietary data observations, but increased the level of detail. Additionally, in the absence of any further refining information, participants were categorized with their lowest relevant MMM. This meant that some participants who may have resided in a higher $\mathrm{MMM}$, or more rural area, were actually classified as living in a more populous region.

\section{Conclusions}

Our data provide evidence that rural events provide an ideal opportunity for collecting data on rural Australians aged over 65 years, particularly for males who are under-reported in the literature. Our findings also show that there is a need for further research into opportunistic health promotion initiatives that can be applied at these events and that offer education on nutrition, healthy weight, oral health, and managing health conditions by considering the specific needs of this age group.

Author Contributions: Conceptualization, T.L.S. and L.J.B.; methodology, T.L.S., L.A., S.H., and L.J.B.; formal analysis, T.L.S.; investigation, T.L.S., L.W., R.L., K.S., S.H., and L.J.B.; resources, L.J.B.; data curation, T.L.S.; writing—original draft preparation, T.L.S., L.A., L.W., R.L., S.H., and L.J.B.; writing-review and editing, T.L.S., L.A., L.W., R.L., K.S., S.H., and L.J.B.; supervision, T.L.S., K.S., S.H., and L.J.B.; project administration, L.J.B. All authors have read and agreed to the published version of the manuscript.

Funding: This research received no external funding. L.A. is supported by a National Heart Foundation Post-Doctoral Fellowship (102530) and the NHMRC Centre of Research Excellence in Food Retail Environments for Health (RE-FRESH APP1152968).

Institutional Review Board Statement: Ethics was obtained from the University of Newcastle Human Research Ethics Committee (H-2017-0197) and was conducted in accordance with the National Statement on Ethical Conduct in Human Research.

Informed Consent Statement: Informed consent was obtained prior to the collection of data and measurements.

Data Availability Statement: Data may be available upon request to the corresponding author Leanne Brown (Leanne.Brown@newcastle.edu.au). Each request will be considered on a case-bycase basis.

Acknowledgments: The authors wish to acknowledge the contribution of participants in the CHAaRGE:20 study. We also acknowledge the contribution of previous University of Newcastle Bachelor of Nutrition and Dietetics students and staff who have assisted in data collection since 2017.

Conflicts of Interest: The authors declare no conflict of interest.

\section{References}

1. Australian Institute of Health and Welfare. Older Australia at a Glance; AIHW: Canberra, Australia, 2018.

2. Australian Government Department of Health. 2.5.2 Trends in Population Ageing 2008 [Updated April 2008; Cited 2021 17 Sep 2021]. Available online: https:/ / www1.health.gov.au/internet/publications/publishing.nsf/Content/work-res-ruraud-toc \{\}work-res-ruraud-2 \{\}work-res-ruraud-2-5 \{\}work-res-ruraud-2-5-2 (accessed on 17 September 2021). 
3. Rudnicka, E.; Napierala, P.; Podfigurna, A.; Meczekalski, B.; Smolarczyk, R.; Grymowicz, M. The World Health Organization (WHO) approach to healthy ageing. Maturitas 2020, 139, 6-11. [CrossRef] [PubMed]

4. Australian Institute of Health and Welfare. Chronic Condition Multimorbidity; AIHW: Canberra, Australia, 2021.

5. Australian Institute of Health and Welfare. Australian Burden of Disease Study: Impact and Causes of Illness and Death in Australia 2015; Australian Burden of Disease Series; AIHW: Canberra, Australia, 2019.

6. Harris, M.F.; Harris-Roxas, B.; Knight, A.W. Care of patients with chronic disease: Achievements in Australia over the past decade. Med. J. Aust. 2018, 209, 55-57. [CrossRef] [PubMed]

7. Young, K.; Bunn, F.; Trivedi, D.; Dickinson, A. Nutritional education for community dwelling older people: A systematic review of randomised controlled trials. Int. J. Nurs. Stud. 2011, 48, 751-780. [CrossRef] [PubMed]

8. Australian Institute of Health and Welfare. Australian Burden of Disease Study 2018: Key Findings; Australian Burden of Disease Study Series 24; AIHW: Canberra, Australia, 2021.

9. Australian Institute of Health and Welfare. Rural \& Remote Health; AIHW: Canberra, Australia, 2019.

10. Alston, L.; Bourke, L.; Nichols, M.; Allender, S. Responsibility for evidence-based policy in cardiovascular disease in rural communities: Implications for persistent rural health inequalities. Aust. Health Rev. 2020, 44, 527-534. [CrossRef]

11. Alston, L.; Walker, T.; Kent, K. Characterizing Dietary Intakes in Rural Australian Adults: A Systematic Literature Review. Nutrients 2020, 12, 3515. [CrossRef]

12. Australian Government Department of Health. Modified Monash Model 2020. Available online: https://www.health.gov.au/ health-workforce/health-workforce-classifications / modified-monash-model (accessed on 7 February 2020).

13. National Rural Health Alliance. Income Inequality Experienced by the People of Rural and Remote Australia; National Rural Health Alliance: Canberra, Australia, 2014.

14. National Rural Health Alliance \& ACOSS. A Snapshot of Poverty in Rural and Regional Australia; National Rural Health Alliance: Canberra, Australia, 2013.

15. Liaw, S.T.; Kilpatrick, S.E. A Textbook of Australian Rural Health; Australian Rural Health Education Network: Canberra, Australia, 2008.

16. Alston, L.; Peterson, K.L.; Jacobs, J.P.; Allender, S.; Nichols, M. Quantifying the role of modifiable risk factors in the differences in cardiovascular disease mortality rates between metropolitan and rural populations in Australia: A macrosimulation modelling study. BMJ Open 2017, 7, e018307. [CrossRef]

17. Australian Institute of Health and Welfare. Rural and Remote Health Canberra: Australian Institute of Health and Welfare; 2019 [Cited 2019 November]. Available online: https://www.aihw.gov.au/reports/rural-remote-australians/rural-remote-health/ contents/health-status-and-outcomes (accessed on 30 November 2019).

18. Alston, L.; Nichols, M.; Allender, S. Policy makers' perceptions of the high burden of heart disease in rural Australia: Implications for the implementation of evidence-based rural health policy. PLOS ONE 2019, 14, e0215358. [CrossRef]

19. Jacobs, J.; Peterson, K.L.; Allender, S.; Alston, L.V.; Nichols, M. Regional variation in cardiovascular mortality in Australia 2009-2012: The impact of remoteness and socioeconomic status. Aust. N. Z. J. Public Health 2018, 42, 467-473. [CrossRef]

20. Alston, L.; Allender, S.; Peterson, K.; Jacobs, J.; Nichols, M. Rural Inequalities in the Australian Burden of Ischaemic Heart Disease: A Systematic Review. Heart Lung Circ. 2017, 26, 122-133. [CrossRef]

21. Alston, L.; Partridge, S.R. Limited dietary interventions in rural Australian communities: A systematic review. Nutr. Diet. 2021, 78, 57-68. [CrossRef]

22. Australian Bureau of Statistics. 4363.0-National Health Survey: Users' Guide, 2017-2018 Canberra, Australia: Australian Bureau of Statistics; 2019. Available online: https://www.abs.gov.au/ausstats/abs@.nsf/Lookup/by\%20Subject/4363.0 \{\}201718 \{\}Main\%20Features \{\}Structure\%20of\%20the\%20National\%20Health\%20Survey \{\}10 (accessed on 10 November 2019).

23. Fogelholm, M.; Valve, R.; Absetz, P.; Heinonen, H.; Uutela, A.; Patja, K.; Karisto, A.; Konttinen, R.; Mäkelä, T.; Nissinen, A.; et al. Rural-urban differences in health and health behaviour: A baseline description of a community health-promotion programme for the elderly. Scand. J. Public Health 2006, 34, 632-640. [CrossRef]

24. Lubben, J.E.; Weiler, P.G.; Chi, I.; De Jong, F. Health promotion for the rural elderly. J. Rural Health 1988, 4, 85-96. [CrossRef]

25. Seaman, C.E.; Green, E.; Smith, B. Reaching at-risk rural men: An evaluation of a health promotion activity targeting men at a large agricultural event. Health Promot. J. Aust. 2021, 32 (Suppl. 2), 65-71. [CrossRef]

26. Meyer, P. Rural Agricultural Shows in New South Wales, Australia: Marketing Events to Address Decline. In Proceedings of the New Zealand Tourism and Hospitality Research Conference, Wellington, New Zealand, 8-10 December $2004 ;$ p. 246.

27. Irshad, H. Impacts of Community Events and Festivals on Rural Place. Available online: https://www1.agric.gov.ab.ca/ \$Department/deptdocs.nsf/all/csi13702/\$FILE/Community-events-and-festivals.pdf (accessed on 10 November 2019).

28. Baptista Alves, H.M.; María Campón Cerro, A.; Vanessa Ferreira Martins, A. Impacts of small tourism events on rural places. J. Place Manag. Dev. 2010, 3, 22-37. [CrossRef]

29. Department of Health. Draft National Preventive Health Strategy 2021-2030. Available online: .https:/ / consultations.health.gov. $\mathrm{au} /$ national-preventive-health-taskforce/draft-national-preventive-health-strategy/ (accessed on 10 November 2021).

30. Pullen, R.; Kent, K.; Sharman, M.J.; Schumacher, T.L.; Brown, L.J. A Comparison of Diet Quality in a Sample of Rural and Urban Australian Adults. Nutrients 2021, 13, 4130. [CrossRef] [PubMed] 
31. Department of Health. Physical Activity and Exercise Guidelines for All Australians Canberra, Australia: Australian Government; 2021. [Updated 7 May 2021]. Available online: https://www.health.gov.au/health-topics/physical-activity-and-exercise/ physical-activity-and-exercise-guidelines-for-all-australians (accessed on 22 October 2021).

32. Harris, P.A.; Taylor, R.; Minor, B.L.; Elliott, V.; Fernandez, M.; O’Neal, L.; McLeod, L.; Delacqua, G.; Delacqua, F.; Kirby, J.; et al. The REDCap consortium: Building an international community of software platform partners. J. Biomed. Inform. 2019, 95, 103208. [CrossRef]

33. Williams, R.L.; Rollo, M.E.; Schumacher, T.; Collins, C.E. Diet Quality Scores of Australian Adults Who Have Completed the Healthy Eating Quiz. Nutrients 2017, 9, 880. [CrossRef] [PubMed]

34. Collins, C. Healthy Eating Quiz: University of Newcastle. 2013. Available online: https:/ /healthyeatingquiz.com.au/ (accessed on 22 October 2021).

35. Burrows, T.L.; Hutchesson, M.J.; Rollo, M.E.; Boggess, M.M.; Guest, M.; Collins, C.E. Fruit and vegetable intake assessed by food frequency questionnaire and plasma carotenoids: A validation study in adults. Nutrients 2015, 7, 3240-3251. [CrossRef] [PubMed]

36. Collins, C.E.; Burrows, T.L.; Rollo, M.E.; Boggess, M.M.; Watson, J.F.; Guest, M.; Duncanson, K.; Pezdirc, K.; Hutchesson, M.J. The comparative validity and reproducibility of a diet quality index for adults: The Australian Recommended Food Score. Nutrients 2015, 7, 785-798. [CrossRef] [PubMed]

37. National Health and Medical Research Council. Australian Guide to Healthy Eating. Canberra: NHMRC; 2013 [Updated 1 May 2017]. Available online: https://www.eatforhealth.gov.au/guidelines/australian-guide-healthy-eating (accessed on 3 October 2021).

38. Australian Government. Waist Circumference Canberra: Department of Health. 2014. Available online: https://healthyweight. health.gov.au/wps/portal/Home/get-started/are-you-a-healthy-weight/waist-circumference (accessed on 22 October 2021).

39. World Health Organization. Obesity: Preventing and Managing the Global Epidemic; Contract No.: 894; WHO: Geneva, Switzerland, 2000.

40. Barclay, L.; Phillips, A.; Lyle, D. Rural and remote health research: Does the investment match the need? Aust. J. Rural Health 2018, 26, 74-79. [CrossRef]

41. Ryan, J.; Lopian, L.; Le, B.; Edney, S.; Van Kessel, G.; Plotnikoff, R.; Vandelanotte, C.; Olds, T.; Maher, C. It's not raining men: A mixed-methods study investigating methods of improving male recruitment to health behaviour research. BMC Public Health 2019, 19, 814. [CrossRef] [PubMed]

42. Punt, S.E.; Kurz, D.L.; Befort, C.A. Recruitment of Men into a Pragmatic Rural Primary Care Weight Loss Trial. Am. J. Mens Health 2020, 14, 1557988320971917. [CrossRef] [PubMed]

43. Australian Institute of Health and Welfare. Health of Older People Canberra, Australia: AIHW; 2020. Available online: https:/ / www.aihw.gov.au/reports/australias-health/health-of-older-people (accessed on 22 October 2021).

44. Keyes, K.M.; Rutherford, C.; Popham, F.; Martins, S.S.; Gray, L. How Healthy Are Survey Respondents Compared with the General Population?: Using Survey-linked Death Records to Compare Mortality Outcomes. Epidemiology 2018, 29 , $299-307$. [CrossRef] [PubMed]

45. National Seniors. Just Doing It!? Older Australians' Physical Activity: National Seniors; 2020 [10/11/2021]. Available online: https:/ / nationalseniors.com.au/uploads/JustDoingIt-RsrchRpt.pdf (accessed on 22 October 2021).

46. Alston, L.; Green, M.; Versace, V.L.; Bolton, K.A.; Widdicombe, K.; Buccheri, A.; Imran, D.; Allender, S.; Orellana, L.; Nichols, M. Profiling Malnutrition Prevalence among Australian Rural In-Patients Using a Retrospective Census of Electronic Medical Files over a 12-Month Period. Int. J. Environ. Res. Public Health 2020, 17, 5909. [CrossRef]

47. Tanumihardjo, S.A.; Anderson, C.; Kaufer-Horwitz, M.; Bode, L.; Emenaker, N.J.; Haqq, A.M.; Satia, J.A.; Silver, H.J.; Stadler, D.D. Poverty, obesity, and malnutrition: An international perspective recognizing the paradox. J. Am. Diet. Assoc. 2007, 107, 1966-1972. [CrossRef]

48. Visvanathan, R.; Yu, S. Position Statement No 6. Undernutrition and the Older Person; Australian and New Zealand Society for Geriatric Medicine: Waitangi, New Zealand, 2015.

49. National Rural Health Alliance. Health Workforce Canberra, Australia 2021. Available online: https://www.ruralhealth.org.au/ advocacy / current-focus-areas / health-workforce (accessed on 22 October 2021).

50. Smith, T.; Sutton, K.; Beauchamp, A.; Depczynski, J.; Brown, L.; Fisher, K.; Waller, S.; Wakely, L.; Maybery, D.; Versace, V.L. Profile and rural exposure for nursing and allied health students at two Australian Universities: A retrospective cohort study. Aust. J. Rural Health 2021, 29, 21-33. [CrossRef]

51. Toniazzo, M.P.; Amorim, P.S.; Muniz, F.; Weidlich, P. Relationship of nutritional status and oral health in elderly: Systematic review with meta-analysis. Clin. Nutr. 2018, 37, 824-830. [CrossRef]

52. Schwingshackl, L.; Bogensberger, B.; Hoffmann, G. Diet Quality as Assessed by the Healthy Eating Index, Alternate Healthy Eating Index, Dietary Approaches to Stop Hypertension Score, and Health Outcomes: An Updated Systematic Review and Meta-Analysis of Cohort Studies. J. Acad. Nutr. Diet. 2018, 118, 74-100.e11. [CrossRef]

53. Whatnall, M.C.; Patterson, A.J.; Ashton, L.M.; Hutchesson, M.J. Effectiveness of brief nutrition interventions on dietary behaviours in adults: A systematic review. Appetite 2018, 120, 335-347. [CrossRef]

54. Australian Bureau of Statistics. Regional Population by Age and Sex Canberra: Australian Government. 2020. Available online: https://www.abs.gov.au/statistics/people/population/regional-population-age-and-sex/2020 (accessed on 22 October 2021). 